\title{
Dynamic Currency Intervention and International Monetary Neutrality
}

\author{
Hailong Jin, Tong Wang \\ South Dakota State University, Brookings, USA \\ Email: hailong.jin@sdstate.edu
}

How to cite this paper: Jin, H.L. and Wang, T. (2017) Dynamic Currency Intervention and International Monetary Neutrality. Theoretical Economics Letters, 7, 575-581.

https://doi.org/10.4236/tel.2017.73042

Received: February 21, 2017

Accepted: April 17, 2017

Published: April 20, 2017

Copyright $\odot 2017$ by authors and Scientific Research Publishing Inc. This work is licensed under the Creative Commons Attribution International License (CC BY 4.0).

http://creativecommons.org/licenses/by/4.0/

\section{(c) (i) Open Access}

\begin{abstract}
Modeling the regime of long run exchange rate and capital account intervention, or dynamic currency intervention (DCI), widely adopted by emerging economies, is of great importance to international economists. This paper develops a new dynamic general equilibrium model to probe the key mechanism of a DCI regime. We show clear drawbacks of models investigating the two crucial features of DCI separately. On one side, the fast capital market adjustment assumption in existing exchange rate intervention models may not be true for a long run capital market intervention economy. On the other side, the monetary neutrality treatment in long run capital control models can be violated in a strict exchange rate intervention country. Having addressed both issues, the new model in this paper provides an important reference to study the key mechanism of a DCI economy comprehensively.
\end{abstract}

\section{Keywords}

Currency Intervention, Capital Control, General Equilibrium, Monetary Neutrality

\section{Introduction}

Modeling dynamic currency intervention (DCI) regime widely adopted by emerging economies, especially China, has posed great challenge to international economists. Existing models on DCI usually examine its two core features, exchange rate intervention and capital market controls, separately. For example, Edwards and Vegh [1], Drazen [2], Flood and Jeanne [3], Lahiri and Vegh [4] scrutinize the implications of exchange rate intervention on short-run monetary policies; while Prasad et al. [5]; Mendoza et al. [6], Song et al. [7]; Gourinchas and Jeanne [8] investigate the impacts of capital market controls on long-term capital misallocation and global imbalance issues. In comparison, few researches have scrutinized the combined effects of these two features. 
This paper fills this gap by developing a concise dynamic general equilibrium model that incorporates both features of DCI. We postulate that capital markets may adjust slower than commodity markets in DCI countries due to fast global commodity market integration and slow domestic financial market liberalization. This property is different from the short-run exchange rate intervention models, which generally adopt the fast capital market adjustment assumption of liberalized financial market models [9]. Based on the new model, we further investigate the implications of DCI policy on the neutrality of money. We find that international monetary neutrality can be violated if certain strict conditions are not satisfied. This result imposes a limitation on long-term current market control models, which explicitly or implicitly assume "money is neutral" in the long run.

In general, the model can serve as an important reference to study the key mechanism of a DCI regime comprehensively. Nonetheless, it worth noting that given the simple nature of the model, it cannot describe detailed interactions among different sectors. To achieve these tasks, it should be extended to more delicate models, such as multi-country linkage models and dynamic stochastic general equilibrium models.

The organization of the paper is as follows. First, we develop the benchmark DCI model in Section 2. Then we derive its solutions and the associated international monetary stability/neutrality condition in Section 3. Finally, we conclude the paper in Section 4.

\section{The Model}

Without loss of generality, assume that a multi-period global economy consists of only two countries, a DCI country and an international currency issuer, vividly named as China and US respectively. The initial commodity price level in China is normalized to unity but can be adjusted over time. The economy of US is relatively stable, where the price is fixed at an exogenous level. The nominal exchange rate is sustained by the People's Bank of China (PBoC) at 1 unit of Chinese currency (RMB)equating $\varepsilon$ units of US currency (USD).

\subsection{Current Account (CA) Function}

Assuming that the ratio of the real CA to real output is determined by two factors: China-US commodity market integration level and exchange misalignment rate, we have

$$
S_{t}=\theta\left(1-\varepsilon P_{t} / \varepsilon^{o}\right) Y_{t},
$$

where $S_{t}$ and $Y_{t}$ denote USD-valued CA and real output in China respectively; $P_{t}$ denotes the commodity price level in China at time $t$ with $P_{0}$ being normalized to unity $\left(P_{0}=1\right) ; \theta>0$ characterizes the commodity market integration level between China and US; $\varepsilon^{o}$ is the balanced real exchange rate, i.e., $1 \mathrm{RMB}=\varepsilon^{\circ} \mathrm{USD}$, using $t=0$ as the base time. In particular, as $\theta$ and $\varepsilon^{\circ}$ are mainly determined by structural statuses which usually change sluggishly com- 
pared with $S_{t}$ and $Y_{t}$, we assume they are constants in the benchmark model.

\subsection{Commodity Price Function}

Due to strict capital controls by $\mathrm{PBoC}$, the asset markets are greatly distorted in China. For example, numerous signs have revealed that many heavy industries in China, such as chemical and steel industries, were severely overinvested. Nonetheless, the excess supply of commodity in China can still be easily digested by the swift credit expansion in US as the China-US commodity market is well integrated and the US financial market is fully developed. Thus, different from the sluggish commodity market adjustment assumption in current exchange rate intervention models, this paper assumes that the quantity theory of money holds perfectly in China, and define the commodity price as follows:

$$
P_{t}=M_{t} v / Y_{t}
$$

where $M_{t}$ and $v$ are supply and velocity of money respectively. As velocity of money is generally more stationary than price levels in reality, we also treat it as a constant in the benchmark model.

\subsection{Real Output Function}

From tangible goods perspective, slow capital market adjustment can also be mirrored by stable output growth: as asset markets adjust slowly, the output growth in China generally follows a momentum. Thus we define the real output function in China as follows:

$$
\dot{Y}_{t}=g Y_{t},
$$

where $g$ is the spot growth rate of the real output. In particular, we assume $g$ is a constant in the benchmark model to reflect its inertial motion.

\subsection{Money Supply Function}

We assume money supply in China consists of two components: (1) government funds, which are used to purchase state assets, e.g., treasury bonds; and (2) FX funds, which are used to purchase CA from the public. The growth rate of money supply, $\dot{M}_{t}$, accordingly, can be expressed as:

$$
\dot{M}_{t}=\rho M_{t}+S_{t} / \varepsilon,
$$

where $S_{t} / \varepsilon$ is the RMB-valued $\mathrm{CA}$ at time $t ; \rho$ is the exogenous monetary growth rate which reflects $\mathrm{PBoC}$ 's incentive in holding state assets: all else equal, a larger $\rho$ associates with an higher state credit or looser fiscal budget constraint, and vice versa.

\subsection{Remarks}

Equation system (1) to (4) can be used as a fundamental model to investigate the key mechanism of a typical DCI regime. Firstly, the CA equation links global imbalance with real exchange change rate misalignment and commodity market development. Secondly, the commodity price equation reflects the property of 
slow domestic financial market liberalization compared with fast global commodity market integration. Thirdly, the real output growth equation also mirrors the distorted domestic capital market but from a conjugate perspective. Finally, the money supply equation, addresses macroeconomic policy interventions, both monetarily and fiscally, in domestic economy.

\section{Solutions to DCI Model and International Monetary Stability/Neutrality Condition}

The neutrality of money is a crucial assumption on long run capital control models. Although this property may be true in single economy, it may not hold well in international markets where multiple countries' monetary policies interact with each other through FX markets. We now explore the associated international monetary neutrality condition with the model.

\subsection{Solutions to DCI Model}

Combining (1), (2) and (4), we have

$$
\dot{M}_{t}=\left(\rho-\theta v / \varepsilon^{o}\right) M_{t}+\theta Y_{t} / \varepsilon
$$

which can further form the following matrix exponential function with (3):

$$
\dot{u}_{t}=A u,
$$

where $u_{t} \equiv\left[\begin{array}{c}Y_{t} \\ M_{t}\end{array}\right]$ is a variable vector and $A \equiv\left[\begin{array}{cc}g & 0 \\ \theta / \varepsilon & \rho-\theta v / \varepsilon^{o}\end{array}\right]$ is a $2 \times 2$ square matrix, whose two eigenvalues are $\lambda_{1}=g, \lambda_{2}=\rho-\theta v / \varepsilon^{o}$ respectively.

Expressing the solution to (6) as $u_{t}=u_{0} \exp (A t)$ and applying matrix Taylor series expansion on it, we can solve the DCI model as Table 1.

\subsection{International Monetary Stability/Neutrality Condition}

To avoid excessive RMB-USD exchange rate misalignment and guarantee the stability of the international monetary system, the Chinese commodity price should not grow or decay indefinitely. From Table 1, we can see that this condition can only be satisfied if $\lambda_{2}-\lambda_{1}<0$. Thus we have the following international monetary stability condition:

Table 1. Solutions to DCI model.

\begin{tabular}{ccc}
\hline & (i) $\lambda_{1}=g \neq \lambda_{2}=\rho-\theta v / \varepsilon^{o}$ & (ii) $\lambda_{1}=\lambda_{2}=g$ \\
\hline CA & $S_{t}=\theta Y_{0}\left[k_{3} \exp \left(\lambda_{1} t\right)+k_{4} \exp \left(\lambda_{2} t\right)\right]$ & $S_{t}=\theta\left(1-\varepsilon / \varepsilon^{o}-\theta t / \varepsilon^{o}\right) \exp (g t)$. \\
Price & $P_{t}=k_{1} v+k_{2} v \exp \left[\left(\lambda_{2}-\lambda_{1}\right) t\right]$ & $P_{t}=1+\theta t / \varepsilon$ \\
Output & $Y_{t}=Y_{0} \exp \left(\lambda_{1} t\right)$ & $Y_{t}=Y_{0} \exp (g t)$ \\
Money Supply & $M_{t}=k_{1} Y_{0} \exp \left(\lambda_{1} t\right)+k_{2} Y_{0} \exp \left(\lambda_{2} t\right)$ & $M_{t}=(1+\theta t / \varepsilon) Y_{0} \exp (g t) / v$.
\end{tabular}

Note: Here $k_{1}=\frac{\theta / \varepsilon}{\lambda_{1}-\lambda_{2}}, k_{2}=v^{-1}-k_{1}, k_{3}=\frac{g-\rho}{\lambda_{1}-\lambda_{2}}, k_{4}=1-\varepsilon / \varepsilon^{\circ}-k_{3} . \quad \theta, v, g$ and $\rho$ are commodity market integration level, velocity of money, output growth rate and exogenous expansionary rate respectively. 


$$
\rho-g<\theta v / \varepsilon^{o}
$$

Prices in other schemes $\left(\lambda_{2}-\lambda_{1}>0\right.$ and $\left.\lambda_{2}-\lambda_{1}=0\right)$ would all grow indefinitely.

From (7), we can see that high economic growth rate $(g)$, commodity and financial market development levels ( $\theta$ and $v$ ) would loosen the inequality, while low exogenous expansionary rate $(\rho)$ would tighten it, we have the following proposition:

Proposition: A country with slow economic growth, underdeveloped commodity and financial markets and excessive expansionary rate cannot sustain DCI persistently.

Moreover, from Table 1, we can also see that nominal values, such as commodity price $P_{t}$ and nominal exchange rate $\varepsilon$, generally has no impacts on the long run real values under (7). For example, Figure 1 shows that both long run inflation rate gap between China and US and long run CA-to-output ratio are mainly determined by the structural factors $g$ and $\rho$ (rho). In comparison, the nominal exchange rate level (e) exerts little influence. In this sense, (7) also refers to the international monetary neutrality condition.

In other words, although the monetary neutrality generally holds well in a single country, it may not be true in international economy where some key countries intervene their exchange rate and capital markets heavily. To achieve this property, DCI countries are required to conduct relatively weak inflation/monetary controls on one hand and satisfy certain macroeconomic structural condition(s) on the other. Failing to meet either requirement may substantially distort the international monetary system. Indubitably, this result would

(a) Inflation ( $g=.1$, rho $=.05)$

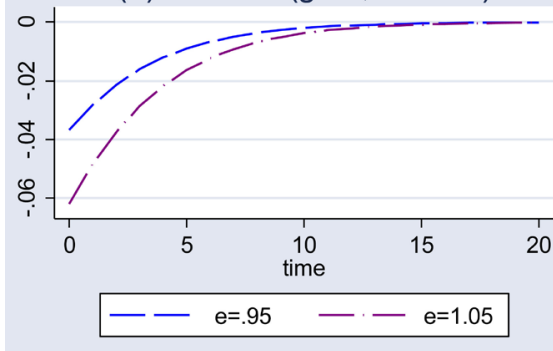

(c) $S / Y(g=.1$,rho $=.05)$

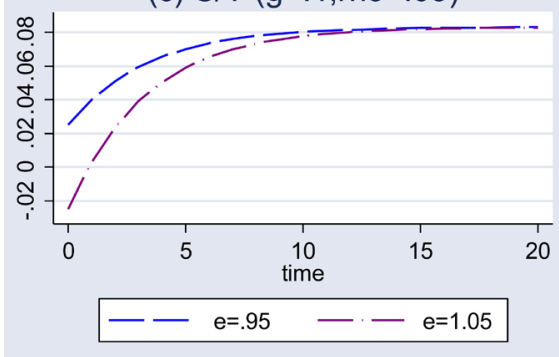

(b) Inflation $(\mathrm{g}=.05$, rho $=.1)$

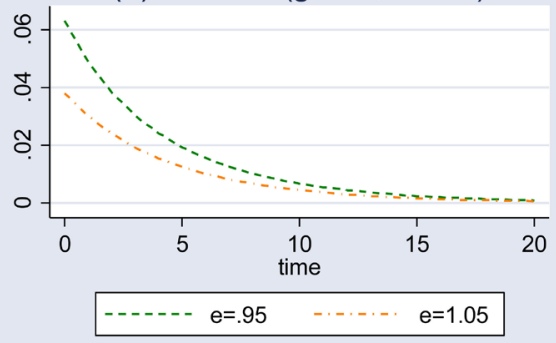

(d) $S / Y(g=.05$,rho $=.1)$

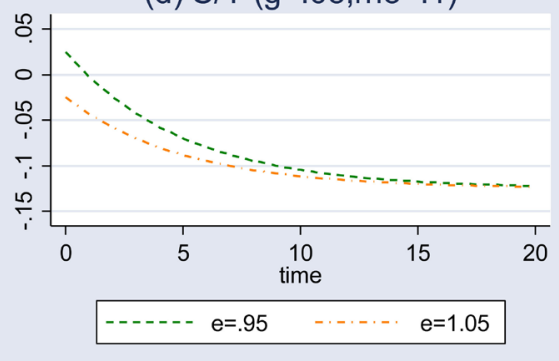

Note: Results are based on solutions in Table 1. Also, without loss of generality, we assume $\varepsilon^{o}, \theta$, and $v$ are equal to one in the simulation.

Figure 1. Inflation rates and CA-output ratios under different exchange rates. 
inevitably impair the effectiveness of current long-term current account control models, which explicitly or implicitly in her it the monetary neutrality assumption.

\section{Concluding Remarks}

We have developed a new dynamic general equilibrium model to investigate the key mechanism of a DCI regime with two core features: long run exchange rate intervention and capital control. We point out that different from standard exchange rate intervention models with fast financial market adjustment assumption, financial markets in DCI countries with strict capital controls may adjust slower than commodity markets. Following this idea, we assume that quantity theory of money holds perfectly, and real output growth is stable in our model.

Based on the model, we further investigate the implications of DCI on international monetary neutrality. Although this property has been widely adopted in current long run capital control models, we show that it can be easily violated in reality. Thus these models have clear limitations in studying the key functioning of a DCI economy.

Given the concise nature of the model, we only describe the fundamental interactions among key macroeconomic sectors. However, as a pioneer research investigates the two core features of DCI comprehensively, the paper provides useful reference to both theoretical and empirical studies. From theoretical perspective, it can be a benchmark framework for more complicated DCI models, such as stochastic and multi-country general equilibrium models. From empirical perspective, it can be used as an important guidance for related empirical analysis, such as econometric modelling and economic puzzle interpretation.

\section{References}

[1] Edwards, S. and Végh, C. (1997) Banks and Macroeconomic Disturbances under Pre-Determined Exchange Rates. Journal of Monetary Economics, 40, 239-278. https://doi.org/10.1016/S0304-3932(97)00043-3

[2] Drazen, A. (2003) Interest Rate Defense against Speculative Attack as a Signal: A Primer. In: Dooley, M.P. and Frankel, J.A., Eds., Managing Currency Crises in Emerging Markets, University of Chicago Press, 37-60.

[3] Flood, R. and Jeanne, O. (2005) An Interest Rate Defense of a Fixed Exchange Rate? Journal of International Economics, 66, 471-484. https://doi.org/10.1016/j.jinteco.2004.09.001

[4] Lahiri, A. and Vegh, C.A. (2005) Output Costs, Currency Crises and Interest Rate Defence of a Peg. Economic Journal, 117, 216-239. https://doi.org/10.1111/j.1468-0297.2007.02008.x

[5] Prasad, E., Rajan, R. and Subramanian, A. (2007) Foreign Capital and Economic Growth. Brookings Papers on Economic Activity, 153-230. https://doi.org/10.1353/eca.2007.0016

[6] Mendoza, E.G., Quadrini, V. and Ríos-Rull, J.-V. (2009) Financial Integration, Financial Development, and Global Imbalances. Journal of Political Economy, 117, 371-416. 
[7] Song, Z., Storesletten, K. and Zilibotti, F. (2011) Growing Like China. American Economic Review, 101, 202-241. https://doi.org/10.1257/aer.101.1.196

[8] Gourinchas, P.-O. and Jeanne, O. (2013) Capital Flows to Developing Countries: The Allocation Puzzle. Review of Economic Studies, 1-32.

[9] Dornbusch, R. (1976) Expectations and Exchange Rate Dynamics. Journal of Political Economy, 84, 1161-1176. https://doi.org/10.1086/260506

Submit or recommend next manuscript to SCIRP and we will provide best service for you:

Accepting pre-submission inquiries through Email, Facebook, LinkedIn, Twitter, etc. A wide selection of journals (inclusive of 9 subjects, more than 200 journals) Providing 24-hour high-quality service User-friendly online submission system Fair and swift peer-review system Efficient typesetting and proofreading procedure Display of the result of downloads and visits, as well as the number of cited articles Maximum dissemination of your research work

Submit your manuscript at: http://papersubmission.scirp.org/ Or contact tel@scirp.org 